\title{
Metabolomics study of the therapeutic mechanism of Schisandra Chinensis lignans in diet-induced hyperlipidemia mice
}

\author{
Jing-Hui Sun ${ }^{1}$, Xu Liu', Li-Xin Cong ${ }^{2}$, He Li ${ }^{1}$, Cheng-Yi Zhang ${ }^{1}$, Jian-Guang Chen ${ }^{1 *}$ and Chun-Mei Wang ${ }^{1 *}$
}

\begin{abstract}
Background: Schisandra, a globally distributed plant, has been widely applied for the treatment of diseases such as hyperlipidemia, fatty liver and obesity in China. In the present work, a rapid resolution liquid chromatography coupled with quadruple-time-of-flight mass spectrometry (RRLC-Q-TOF-MS)-based metabolomics was conducted to investigate the intervention effect of Schisandra chinensis lignans $(\mathrm{SCL})$ on hyperlipidemia mice induced by high-fat diet (HFD).
\end{abstract}

Methods: Hyperlipidemia mice were orally administered with SCL $(100 \mathrm{mg} / \mathrm{kg})$ once a day for 4 weeks. Serum biochemistry assay of triglyceride (TG), total cholesterol (TC), low-density lipoprotein cholesterol (LDL-C) and high-density lipoprotein cholesterol (HDL-c) was conducted to confirm the treatment of SCL on lipid regulation. Metabolomics analysis on serum samples was carried out, and principal component analysis (PCA) and partial least squares-discriminant analysis (PLS-DA) were carried out for the pattern recognition and characteristic metabolites identification. The relative levels of critical regulatory factors of liver lipid metabolism, sterol regulatory element-binding proteins (SREBPs) and its related gene expressions were measured by quantitative real-time polymerase chain reaction (RT-PCR) for investigating the underlying mechanism.

Results: Oral administration of SCL significantly decreased the serum levels of TC, TG and LDL-C and increased the serum level of HDL-c in the hyperlipidemia mice, and no effect of SCL on blood lipid levels was observed in control mice. Serum samples were scattered in the PCA scores plots in response to the control, HFD and SCL group. Totally, thirteen biomarkers were identified and nine of them were recovered to the normal levels after SCL treatment. Based on the Kyoto Encyclopedia of Genes and Genomes (KEGG) pathways analysis, the anti-hyperlipidemia mechanisms of SCL may be involved in the following metabolic pathways: tricarboxylic acid (TCA) cycle, synthesis of ketone body and cholesterol, choline metabolism and fatty acid metabolism. Meanwhile, SCL significantly inhibited the mRNA expression level of hepatic lipogenesis genes such as SREBP-1c, fatty acid synthase (FAS) and acetyl-CoA carboxylase (ACC), and decreased the mRNA expression of liver $X$ receptor a $(L X R a)$. Moreover, $S C L$ also significantly decreased the expression level of SREBP-2 and 3-hydroxy-3-methylglutaryl coenzyme A reductase (HMGCR) in the liver of hyperlipidemia mice.

Conclusion: Anti-hyperlipidemia effect of SCL was confirmed by both serum biochemistry and metabolomics analysis. The mechanism may be related to the down-regulation of LXRa/SREBP-1C/FAS/ACC and SREBP2/HMGCR signaling pathways.

Keywords: Schisandra chinensis lignans, Hyperlipidemia, Metabolomics, RRLC-Q-TOF-MS, RT-PCR

\footnotetext{
*Correspondence: chenjg118@sohu.com; 413437244@qq.com

'College of Pharmacy, Beihua University, 3999 Binjiang East Road, Jilin

132013, China

Full list of author information is available at the end of the article
} 


\section{Background}

Hyperlipidemia is a consternation of several serum lipoprotein abnormalities, such as increased triglyceride (TG), total cholesterol (TC), low-density lipoprotein cholesterol (LDL-c), very low-density lipoprotein cholesterol (VLDL-c), and decreased high-density lipoprotein cholesterol (HDL-c) in serum, and also as one of the major risk factors that cause arteriosclerosis, cerebral stroke, coronary heart disease, myocardial infarction, type 2 diabetes and renal failure [1-4]. Fibrates, statins, bile acid sequestrants, nicotinic acid and cholesterol absorption inhibitors are commonly used for the treatment of hyperlipidemia [5]. But unfortunately, most of these drugs generally have side or toxic effects, such as statin-induced myopathy and fibrate-induced rhabdomyolysis [6, 7]. Therefore, the research and development of safe and effective anti-hyperlipidemia drugs are particularly important.

Schisandra, a famous traditional medicinal material in China, is the dried ripe fruit of Schisandra chinensis (Turcz.) Baill., and widely used for various medicinal purposes, such as hepatoprotection, anti-inflammation, antioxidant property, antitumor activity, and resistance to insulin resistance [8-10]. The main components of Schisandra are lignans, and many research has shown that Schisandra chinensis lignans (SCL) has obvious anti-hyperlipidemia effect, such as reduced hepatic TG and TC levels, in mice with hypercholesterolemia produced by high-fat diet (HFD) containing cholesterol/bile salt, but the therapeutic mechanism was still unclear [11-13].

With the development of gas chromatography/mass spectrometer (GC/MS), liquid chromatography/mass spectrometer (LC/MS), nuclear magnetic resonance (NMR) and related analysis softwares, metabolomics has been widely used to investigate disease diagnosis, biomarker discovery, toxicology and pharmaceutical study by global assessment of living systems metabolites and dynamic responses to pathophysiological stress [14-16]. For hyperlipidemia, metabolomics is widely used in diagnosis, monitoring drug treatment and developing drugs [17-21]. In the present study, with regards to the multifacet mechanisms of hyperlipidemia and holistic effects of SCL, a RRLC-Q-TOF-MS-based metabolomic approach was developed to evaluate the anti-hyperlipidemia effect of SCL by analyzing the characteristics of mouse hyperlipidemia induced by HFD and the mechanism was also investigated by observing the related protein gene expression.

\section{Experimental materials}

\section{Experimental animals and feed preparation}

Forty eight male C57BL/6 mice, weighing 19 to $21 \mathrm{~g}$, were provided by Beijing Weitonglihua Experimental Animal Technology Co. Ltd. [license number: SCXK (Beijing) 2015-0001, specific pathogen free (SPF)]. The mice were housed in separate cages, with an intake of about $5 \mathrm{~g}$ feed/mouse daily and access to water freely. The animal room was disinfected once a week, the temperature was controlled at about $22{ }^{\circ} \mathrm{C}$, the humidity was about $50 \%$, the natural diurnal cycle was maintained, the mouse pad was replaced strictly in accordance with the requirements once each three days, and the mice were weighed and recorded twice a week. The animal experiments were approved by the Institutional Animal Care and Use Committee (IACUC) of Beihua University with the permit number: CPBHU IACUC2015-007. All mouse experimental procedures were performed in accordance with the Regulations for the Administration of Affairs Concerning Experimental Animals approved by the State Council of People's Republic of China.

Both the general diet and HFD for the mice were purchased from Changchun City Yisi Experimental Animal Technology Limited Liability Company. The general diet contained 5\% fat, 53\% carbohydrates, $23 \%$ protein, and $19 \%$ other components, and the high-fat diet contained $2 \%$ cholesterol, $0.5 \%$ sodium cholate, $10 \%$ lard, $5 \%$ sugar, and $82.5 \%$ of the general diet.

\section{Chemicals and materials}

HPLC-grade methanol and acetonitrile were purchased from TEDIA (USA). All the reference standards were purchased from Sigma Corporation (St. Louis, Mo, USA). The water used in the experiments was collected from a Milli-Q Ultra-pure water system (Millipore, Billerica, USA). Other chemicals were of analytical grade.

\section{SCL preparation and its method}

Schisandra chinensis was purchased from Jilin Province Jian City Schisandra Planting Base, and identified by Department of Pharmacognosy, College of Pharmacy, Beihua University as the dried ripe fruit of Schisandra [Schisandra chinensis (Turcz.) Baill.]. Schisandra was ground into powders, and the lignans in it were extracted by supercritical $\mathrm{CO}_{2}$ fluid extraction. The extraction procedures included molecular distillation (the distillation temperature: $110{ }^{\circ} \mathrm{C}$, the feed rate: $65 \mathrm{~L} / \mathrm{h}$, and the vacuum degree: $0.7 \mathrm{~Pa}$ ), the treatment with $\mathrm{AB}$ 8 macroporous resin (the total lignans flow: $1.52 \mathrm{mg} /$ $\mathrm{mL}$, the elution rate: $1 \mathrm{~mL} / \mathrm{min}$, the ethanol concentration: $95 \%$, and the elution rate: $78.9 \%$ ), and silica gel column chromatography [200-300-mesh silica gel and elution with 60:1 (V/V) petroleum ether-ethyl acetate]. Finally, the lignan component was obtained and the total lignanoids absorption spectrum was detected at $570 \mathrm{~nm}$ by ultraviolet spectrophotometry. The results showed that the extract purity was $93.5 \%$. The extract could be adjusted a desired concentration by adding distilled water to it and kept at $4{ }^{\circ} \mathrm{C}$ for use. 


\section{Methods}

\section{Establishment of mouse hyperlipidemia model}

Forty eight male mice were randomly divided into control group $(n=24)$ fed with the general diet and hyperlipidemia model $(n=24)$ fed with the HFD. Four weeks later, they were fasted for $12 \mathrm{~h}$, but with free access to water, and then their blood samples were taken from the canthus (in the state of ether anesthesia) for the detection of TC and TG contents in the mice's serum, which could confirm whether the establishment of hyperlipidemia model in mice was successful or not. Twenty four control mice were randomly divided into control group and control + SCL group. Twenty four hyperlipidemia mice were randomly divided into model group and model + SCL group. Mice in both the control group and model group were given an equal volume of distilled water, and those in the model + SCL group and control + SCL group were given SCL (100 mg/kg) intragastrically for 4 weeks successively.

After the end of the administration, the mice were fasted for $12 \mathrm{~h}$, but with free access to water, then were anesthetized with ether and their blood samples were taken by eyeball removal, and the blood samples were centrifuged (at $3500 \mathrm{r} / \mathrm{min}$ and $4{ }^{\circ} \mathrm{C}$, for $10 \mathrm{~min}$ ) to separate the serum for use. Immediately the mice's livers were removed, washed with precooling saline, dried with filter paper, and cryopreserved at $-80{ }^{\circ} \mathrm{C}$ until analysis.

\section{Determination of serum lipids}

Serum levels of TC, TG, LDL-c and HDL-c in serum of mice were assayed using commercially available kits (Nanjing Jiancheng Biotech Inc., Nanjing, China) and the specific procedures were strictly in line with the kit instructions.

\section{RRLC/MS analysis}

$100 \mu \mathrm{L}$ of the serum were added with $1 \mathrm{~mL}$ methanol, which was shaken for $30 \mathrm{~s}$ by a vertex vibrator, and then centrifuged at $13000 \mathrm{r} / \mathrm{min}$ for $5 \mathrm{~min}$ to obtain the supernatants. The supernatants were filtered with $0.22 \mu \mathrm{m}$ filter membranes and the filtered supernatants were kept at $-4{ }^{\circ} \mathrm{C}$ for the analysis.

The rapid resolution liquid chromatography (Agilent 1200 RRLC, Santa Clara, CA, USA) system was equipped with a binary pump, a micro-degasser, an auto-plate sampler, and a thermostatically controlled column apartment. The mass spectrometer (Agilent 6520 Q-TOF MS, Santa Clara, CA, USA) was equipped with an electrospray interface and automatic calibration system.

The liquid chromatography separation was performed on an Agilent SB-C18 column $(100 \mathrm{~mm} \times 3.0 \mathrm{~mm}$, $1.8 \mu \mathrm{m}, 600 \mathrm{bar}$ ) at a temperature of $25{ }^{\circ} \mathrm{C} .0 .1 \%$ formic acid $(\mathrm{v} / \mathrm{v})$ and acetonitrile were used as the mobile phases A and B, respectively. The initial elution was 5\%
$\mathrm{B}$, and the gradient elution was programmed as followed: 0-11 $\min (5 \%-61 \% \mathrm{~B}), 11-20 \mathrm{~min}(61 \%-95 \% \mathrm{~B})$. The flow rate was $0.3 \mathrm{~mL} / \mathrm{min}$. The injected sample volume was $5 \mu \mathrm{L}$. This RRLC system was connected to Q-TOF mass spectrometer.

The Q-TOF-MS scan range was set at $m / z 50-1000$ in both negative and positive modes. The conditions of the ESI source were as follows: drying gas $\left(\mathrm{N}_{2}\right)$ flow rate was $8.0 \mathrm{~L} / \mathrm{min}$, drying gas temperature was set at $350{ }^{\circ} \mathrm{C}$, nebulizer was set as 30 psig, capillary voltage was $3500 \mathrm{~V}$, fragmentor was $175 \mathrm{~V}$, and skimmer was $65 \mathrm{~V}$.

\section{Biomarkers data and statistical analysis}

The analysis of RRLC/MS data was performed on Agilent software Masshunter (version B 03.01) and Mass Profiler Professional (version B 02.02). The parameters were set as follows: Experiment type: Unidentified, Organism: Mus musculus, Minimum absolute abundance: 2000 counts, Compound alignment: $\mathrm{RT}$ window $=0.1 \%+0.15 \mathrm{~min}$ and Mass window $=5.00 \mathrm{ppm}+2.0 \mathrm{mDa}$, and Baseline Option: Z-Transform. After all the data are filtered and normalized, univariate data analysis was carried out using $t$-test and a one-way analysis of variance (ANOVA), with statistical significance set at $P<0.05$. Multivariate data were analyzed using principal component analysis (PCA) and partial least squares-discriminant analysis (PLS-DA). PCA was applied to identify outliers and detect data grouping or separation trends, and it also produced an overview of the data set. In PCA, the samples are classified by score plots and the potential biomarkers are found by loading plots. PLS-DA, focused on the actual class discriminating variation of data compared to the unsupervised approach of PCA. The data were subjected to PLS-DA where to establish the model forecasting. The PLS-DA model was validated by describing $R^{2} Y$ and $Q^{2}$ values, $R^{2}$ describes how well the data could be mathematically reproduced by the training model, the closer the $R^{2}$ and $Q^{2}$ values to 1 , the more stable the model was. For the identification of potential biomarkers, the following databases were used: HMDB [22], LIPID MAPS [23], and KEGG [24].

\section{RNA extraction and real-time reverse transcription polymerase chain reaction (RT-PCR)}

The total RNA was extracted from mouse liver tissues using Trizol reagent (Invitrogen, USA) according to the manufacturer's instruction to investigate effects of SCP on the expression of TG- and TC-related genes. The reverse transcription (RT) by total RNA $(1 \mu \mathrm{g})$, oligo (15) dT, and reverse transcriptase was performed using RT kits (Promega, Beijing, China) in a final volume of $20 \mu \mathrm{L}$. PCR primer sequences were designed using primer 6.0 software and synthesized by Dingguo Changsheng Biotechnology Co. Ltd. (Beijing, China). The gene expression levels were 
analyzed in duplicate using a SYBR Green kit (Promega, Beijing, China) according to the manufacturer's instruction on real-time PCR System (ABI 7500, Biometra, Germany). All the primer lengths and annealing temperatures are listed in Table 1 . The ${ }^{\Delta \Delta} \mathrm{Ct}$ method was used for the relative quantification. The relative gene expression was normalized to the GAPDH expression level, and the ratios were presented as arbitrary units.

\section{Statistical analysis}

All data were expressed as mean \pm standard deviation (SD) $(\bar{x} \pm s)$. " $n$ " denotes the sample numbers in each group. SPSS software (version 19.0 for Windows) was used for the statistical analysis. $P<0.05$ and $P<0.01$ was considered to be statistically significant.

\section{Results}

Changes in blood TC and TG contents in mice on HFD for 4 weeks

As shown in Fig. 1, the content of TC and TG in the model group was significantly higher than that in the control group $(P<0.01)$, indicating that the HFD-induced hyperlipidemia model was successful.

\section{Effects of SCL on blood lipids in hyperlipidemic mice}

Four weeks after the administration, compared with those in the control group, serum TC, TG and LDL-c levels were significantly increased, and the level of HDL$\mathrm{c}$ was significantly reduced in the model group $(P<0.05$ or $P<0.01)$. Compared with those in the model group, serum TC, TG and LDL-c levels were significantly decreased, and the level of HDL-c were significantly increased in SCL group $(P<0.05$ or $P<0.01)$. But the serum TC, TG, LDL-c and HDL-c levels between the control group and control $+\mathrm{SCL}$ group were not

Table 1 Primers used for quantitative real-time PCR

\begin{tabular}{lll}
\hline Genes & Primer sequences & Length \\
\hline SREBP-1C & Forward 5'-GGAGACATCGCAAACAAGC-3' & 273 bp \\
& Reverse 5'-GGTAGACAACAGCCGCATC-3' & \\
SREBP-2 & Forward 5'-CACCCATACTCAGGCTCG-3' & $133 \mathrm{bp}$ \\
& Reverse 5'-GCTTCACAAAGACGCTCAA-3' & \\
FAS & Forward 5'-ATCGCCTATGGTTGTTG-3' & $127 \mathrm{bp}$ \\
& Reverse 5'-TCACGACTGGAGGTTCTA-3' & \\
ACC & Forward 5'-TATCCCAACTCTTCCCTG-3' & $116 \mathrm{bp}$ \\
& Reverse 5'-CCTTCACATAGCCTTCTC-3' & \\
HMGCR & Forward 5'-CTTGACGCTCTTGTGGA-3' & $259 \mathrm{bp}$ \\
& Reverse 5'-CCCTTTGGGTACGG-3' & \\
LXR & Forward 5'-CTCAATGCCTGATGTTTCTCC-3' & 154 bp \\
& Reverse 5'-TGACTCCAACCCTATCCCTAA-3' & \\
\hline
\end{tabular}

significantly different $(P>0.05)$. The results are shown in Fig. 2.

\section{Development of RRLC-Q-TOF-MS method for metabonomic analysis}

In this study, RRLC-Q-TOF-MS analysis was performed to acquire serum metabonomic profiles in positive and negative ion modes. Figure 3 shows the base peak intensity chromatograms (BPI) of serum sample from control, model and SCL mice in negative and positive ion modes. For the method validation study, a quality control (QC) sample was obtained by taking an aliquot of the same volume $(50 \mu \mathrm{L})$ of all the serum samples in this study. The QC sample was measured after every six serum samples during all the LC-MS analyses. Five ions $(\mathrm{m} / z$ 233.2916, 264.1057, 297.6653, 374.1422 and 418.2501) in negative ion mode and five ions $(\mathrm{m} / z$ 203.0476, 246.2360, 274.2675, 302.2976 and 437.1807) in positive ion mode were selected. The extracted ion chromatograms (EIC) of the ten selected ions showed that the system stability (RSDs \%) of retention times, $\mathrm{m} / \mathrm{z}$ and peak areas were $0.07-0.21 \%, 0.0004-0.0009 \%$ and $6.2-9.7 \%$, respectively. The results indicated that there was no significant difference among the every detection of QC sample and the system stability was excellent.

\section{Analysis of serum metabolite profiles}

Based on RRLC-Q-TOF-MS data, the PCA was performed to discover the potential metabolites of serum samples from control, model and SCL mice. PCA, as a common method for multivariate data analysis, can be used to reduce the dimensionality with minimal information loss while retaining the characteristics that contribute most to the variance. Figures 4a-b and 5a-b show the 3D-PCA score plots, in which the scattered points of various samples exhibit an obvious separation in both negative and positive ion modes.

Figures $4 \mathrm{c}-\mathrm{d}$ and $5 \mathrm{c}-\mathrm{d}$ show the loading plots from the results of PCA in negative and positive ion modes, and each spot represents one compound. The spots further from the center were considered to make greater contributions to the classification and more likely to be the potential biomarkers. For the biomarkers of the PCA analysis, the PLS-DA method was used to analyze the whole sample data, the $\mathrm{R}^{2} \mathrm{Y}$ and $\mathrm{Q}^{2}$ score analysis were 0.937 and 0.879 , respectively. The results showed that the validity of current model. Variables important for the projection (VIP) in PLS-DA were used to confirm the potential biomarkers with the VIP values $\geq 1$.

Accordingly, there were 13 potential metabolites which showed significant differences between control and model groups, and 9 of them showed significant differences between model and SCL groups. To identify these potential biomarkers, the retention time, accurate 

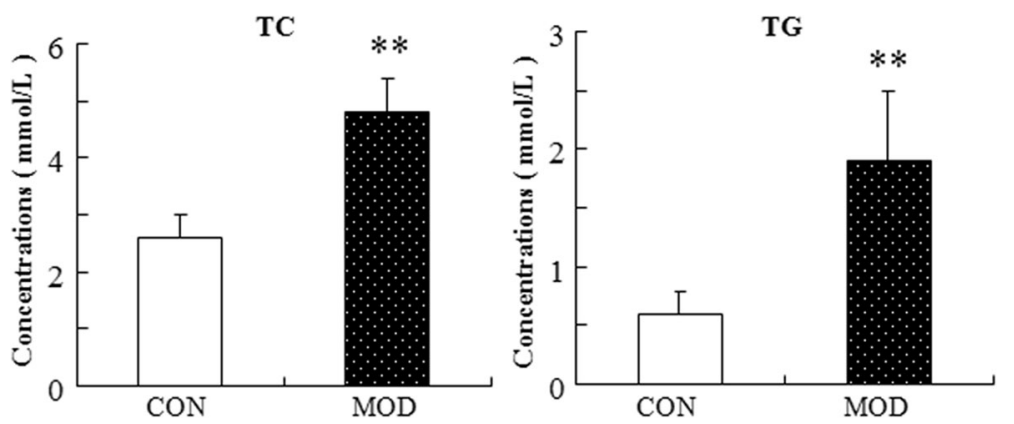

Fig. 1 Comparison on serum TC and TG contents between control and model groups ( $\bar{x} \pm s, n=24)$. Note: CON: control group; MOD: model group. *: Compared with those in the control group, $P<0.01$

molecular ion mass and characteristic MS/MS fragment ions were compared with those of authentic standards and database resources. Table 2 lists the identified biomarkers and the related information.

To observe the trends of these metabolites in each group, the extracted ion chromatogram (EIC) and the average peak area of every biomarker of respective groups were analyzed to achieve the specific peak information for the relative intensity. The peak area of all the metabolites in each group was presented as the mean $\pm \mathrm{SD}$. The statistical analysis was performed by ANOVA and the differences between the means were assessed by Turkey's test. The statistical significance was considered as the value of $P<0.05$ and $P<0.01$. Figure 6 shows the changes of biomarkers in each group.

Effect of SCL on the expression of SREBPs and its related protein genes

As shown in Fig. 7a-d, compared with those in the control group, the key regulator of liver lipid synthesis

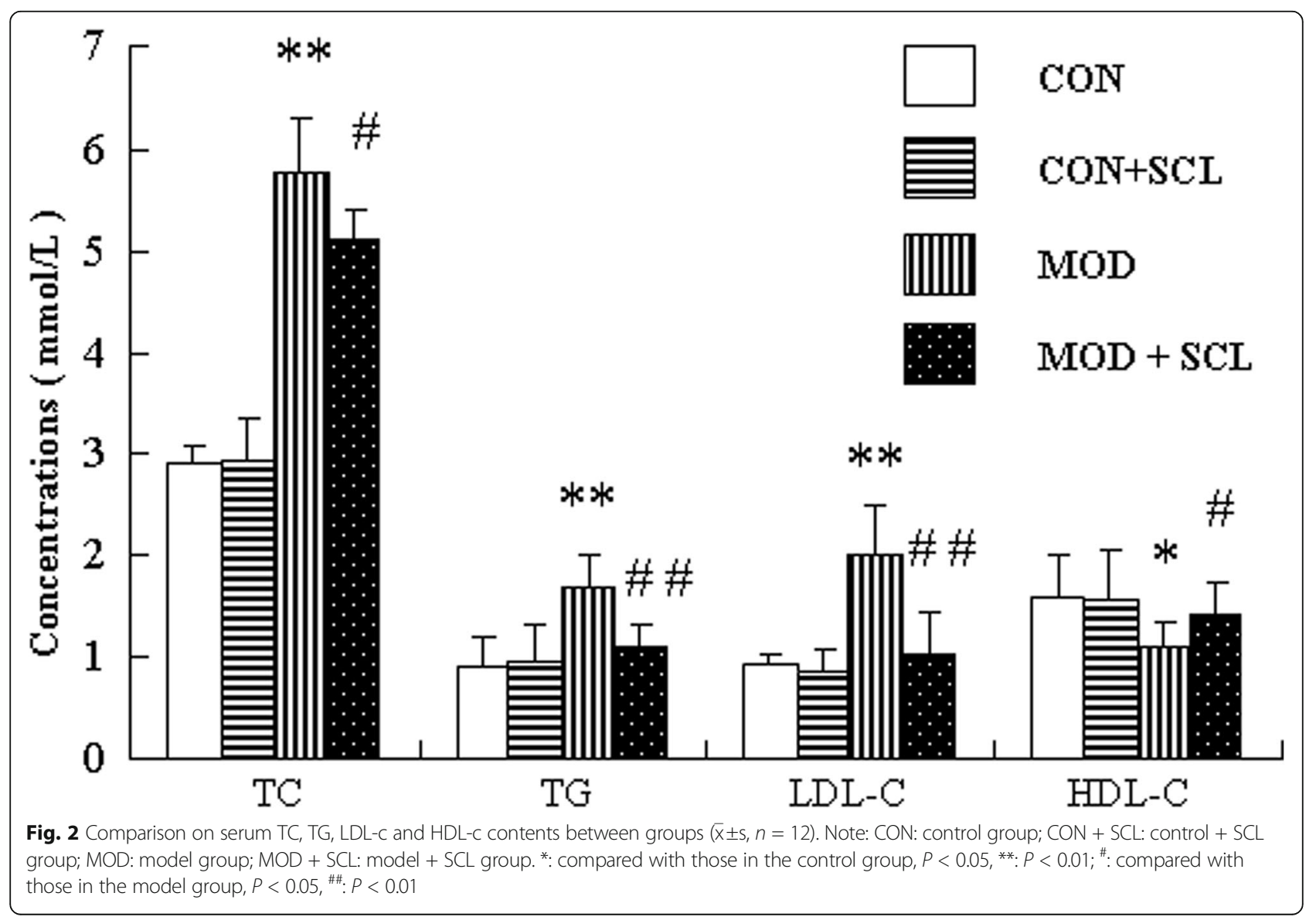



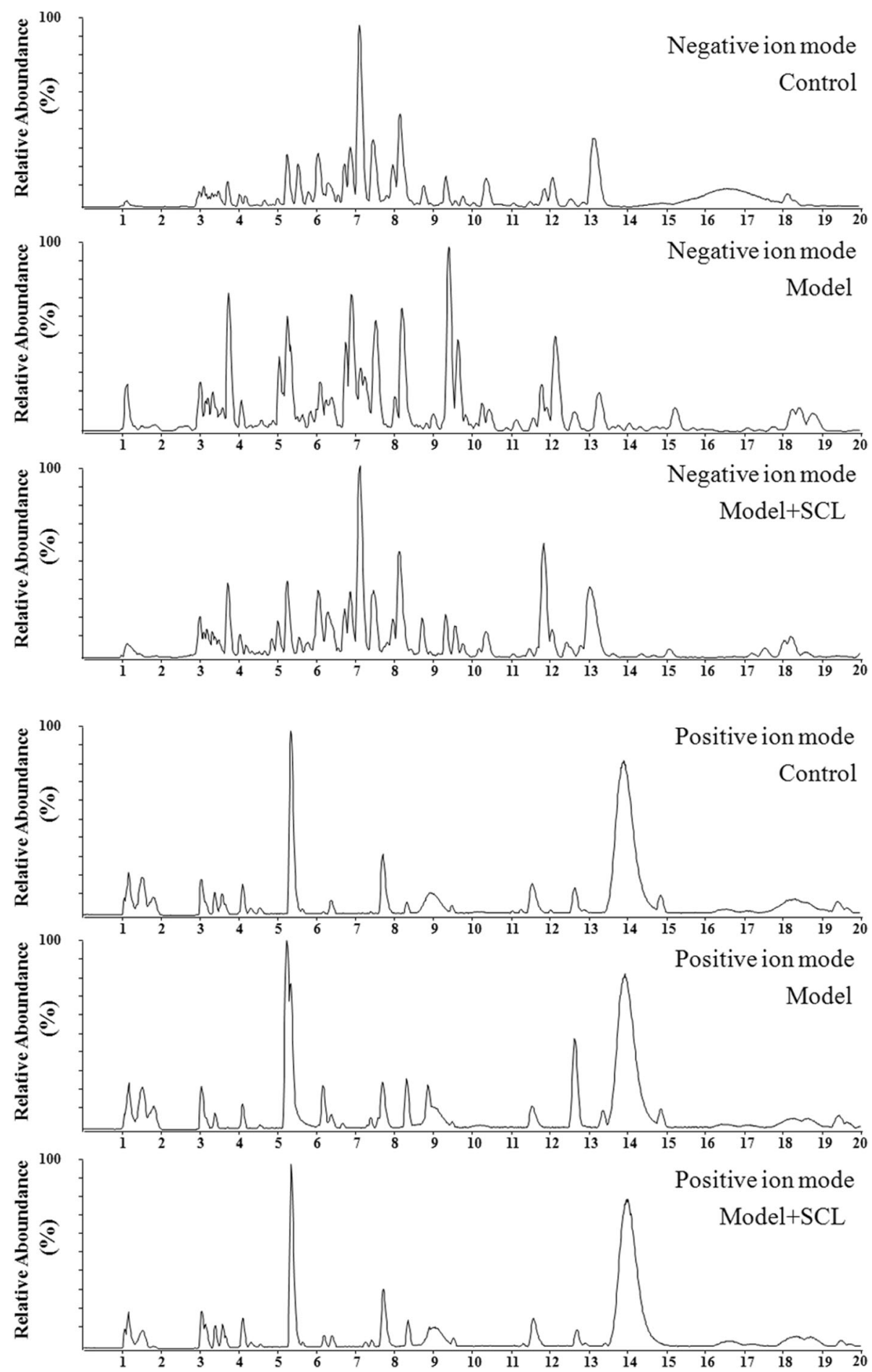

Fig. 3 Base peak intensity (BPI) chromatograms obtained from the negative and positive ion RRLC-Q-TOF-MS analyses of control, model and model + SCL mouse

SREBP-1c and its related gene FAS/ACC expression levels were elevated in the liver of hyperlipidemia mice $(P<0.05)$. Compared with those in the model group, their expression levels were significantly inhibited in the SCL-treated mice $(P<0.05)$, and the expression of hepatic SREBP-1c upstream gene $\mathrm{LXR}_{\alpha}$ was also significantly inhibited $(P<0.05)$. At the same time, the key regulators of hepatic cholesterol synthesis SREBP-2 and HMGCR expressions were also significantly decreased in the SCL-treated mice $(P<0.05)$, as shown in Fig. 8a-b. 

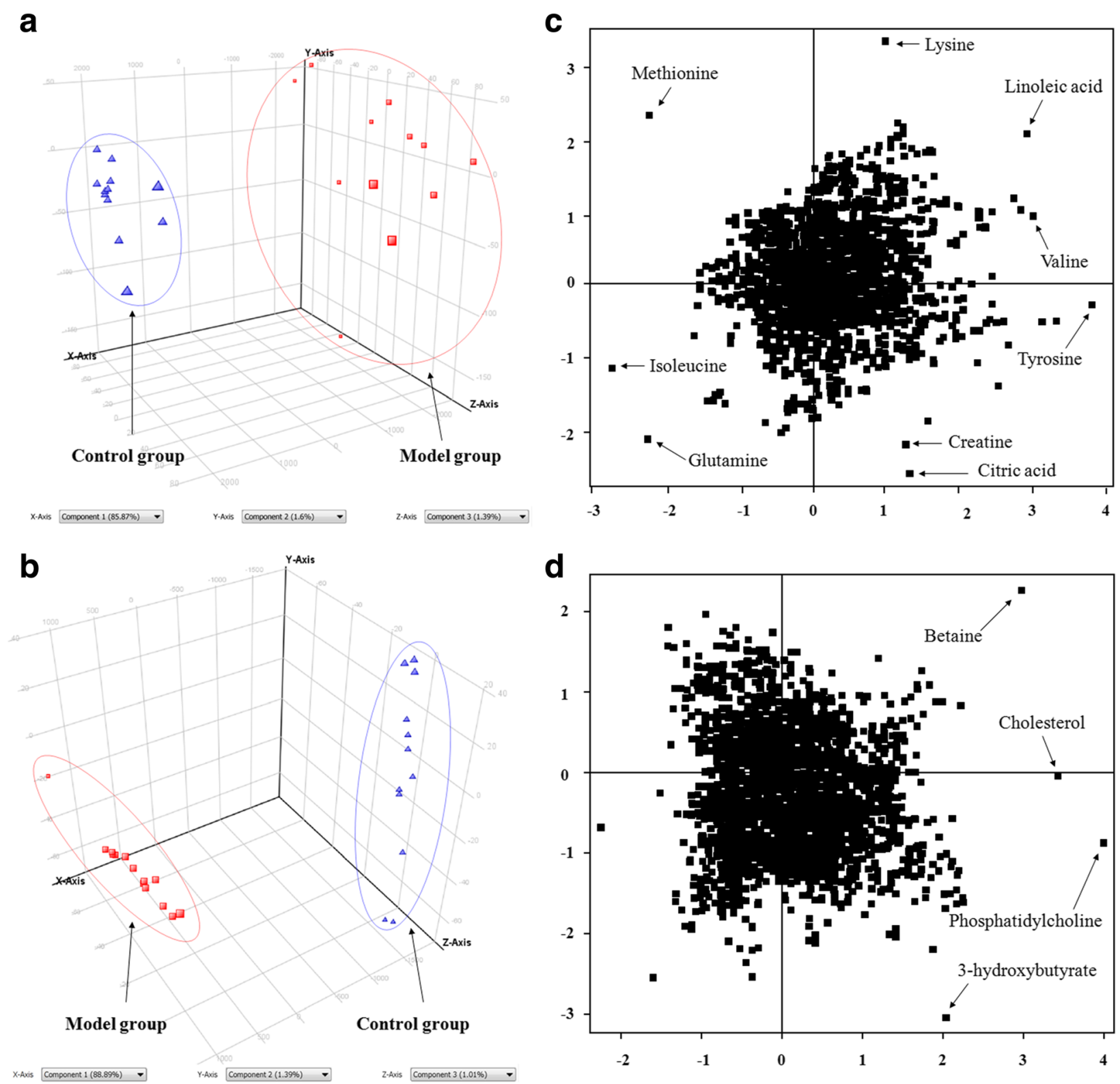

Fig. 4 3D-PCA score plots of control and model group ( $\mathbf{\Lambda}$ : control group; $\mathbf{a}$ : model group)in negative (a) and positive (b) ion mode; loading plots from the result of PCA of control and model group in negative (c) and positive (d) ion mode

The expression level of SREBPs and its related protein genes between the control group and control + SCL group were not significantly different $(P>0.05)$.

\section{Discussions}

Feeding HFD is the most commonly method for animal model of hyperlipidemia [25]. In this study, the serum TC and TG level showed an obviously increase in hyperlipidemia model group after HFD feeding for 4 weeks compared with that in the control group $(P<0.01)$, and 4 weeks after administration of SCL, the serum TC $(P<0.05)$, TG $(P<0.01)$, and LDL-c $(P<0.01)$ were significantly decreased, whereas the serum HDL-c $(P<0.01)$ was significantly increased in SCL group compared with that in the hyperlipidemia model group, but the serum TC, TG, LDL-c and HDL-c levels between the control group and control + SCL group were not significantly different $(P>0.05)$. These changes in the serum biochemical indexes showed that the mouse should have developed a metabolic disorder of lipids and/or lipoproteins in the serum. This indicated that the HFD-induced hyperlipidemia model had been successfully established in the mouse after a continuous administration of a HFD for 4 weeks and SCL could have a significant effect 

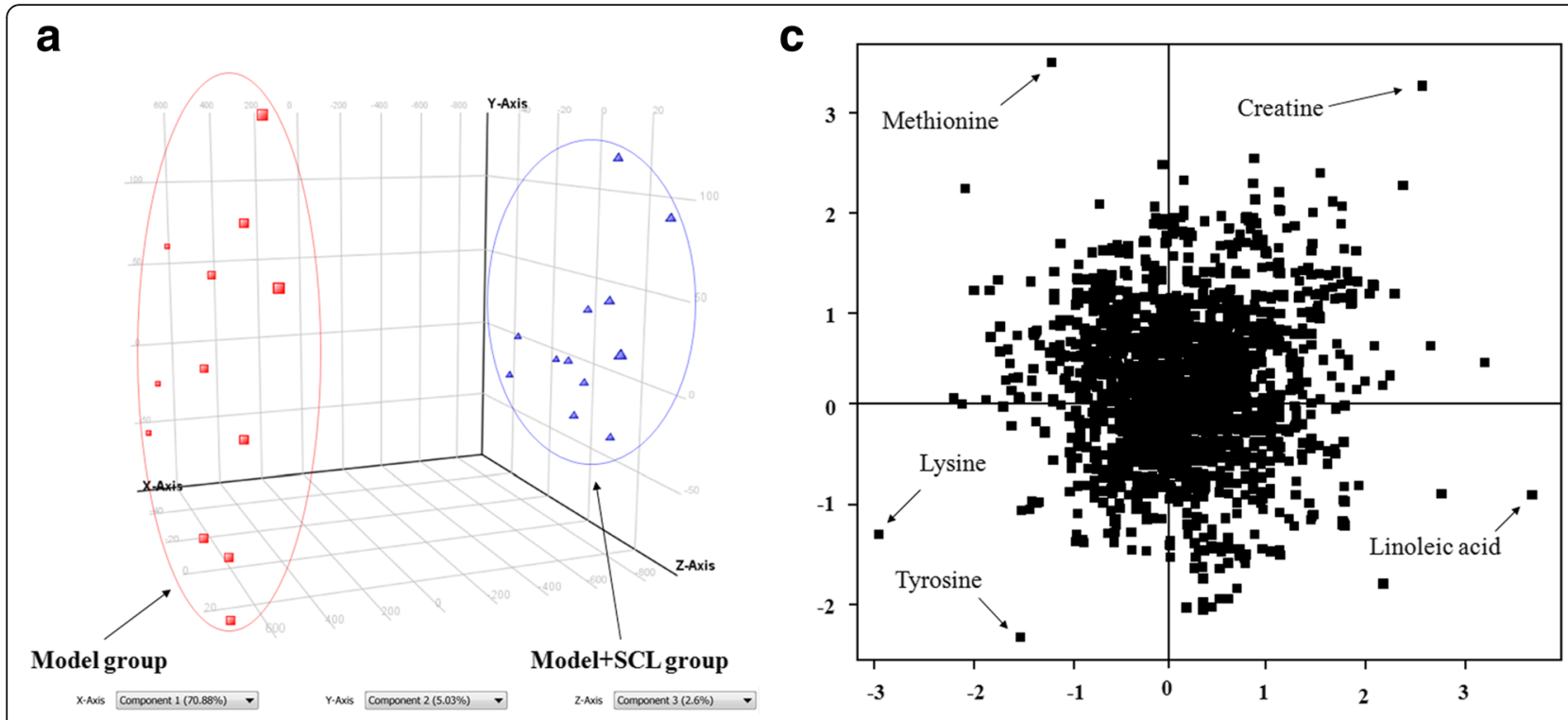

b

d
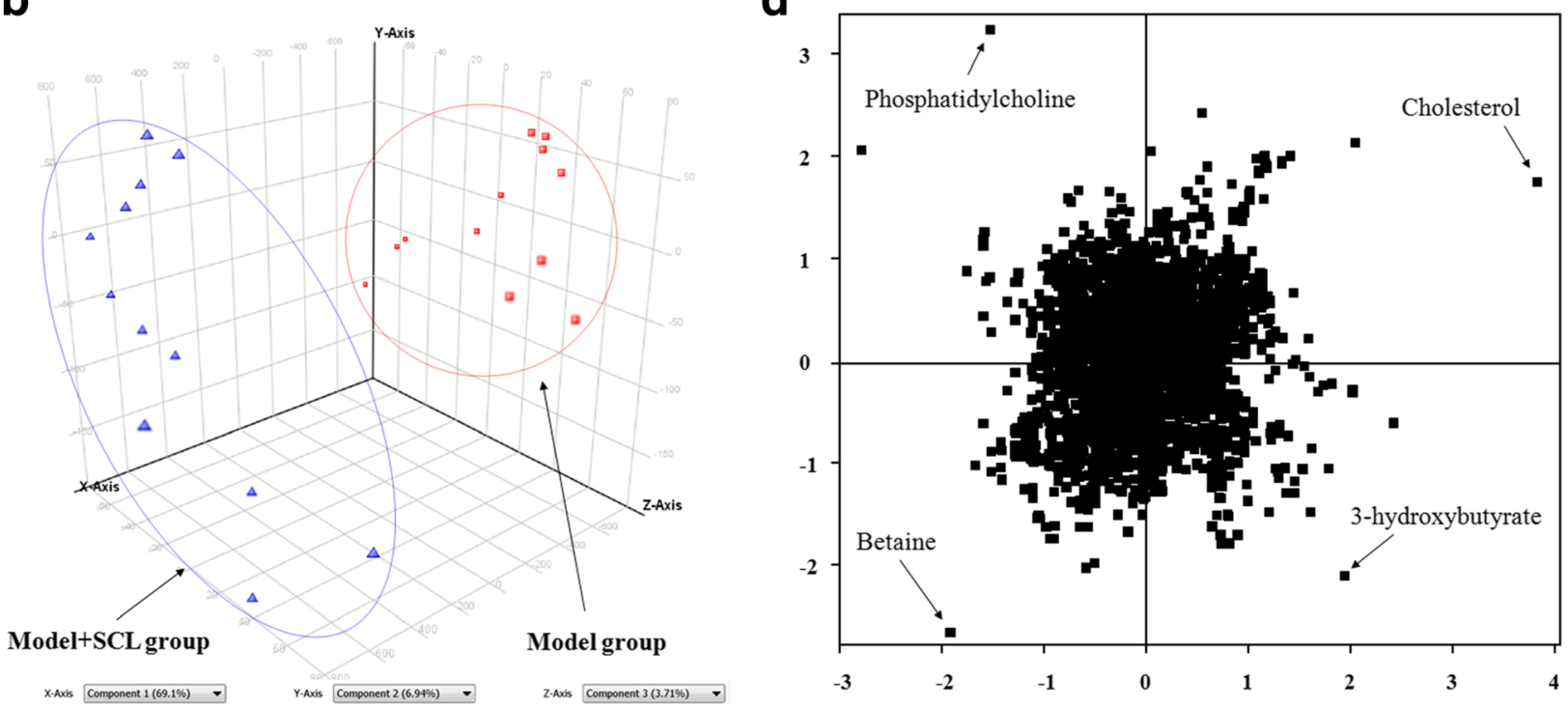

Fig. 5 3D-PCA score plots of model and SCL group ( $\square$ : model group; $\mathbf{\Delta}$ : model + SCL group)in negative (a) and positive (b) ion mode; loading plots from the result of PCA of model and model $+S C L$ group in negative (c) and positive (d) ion mode

on lipid metabolism disorders, but no effects on normal mice, which was also verified by the metabolomics analysis in the scores plot.

The study demonstrated that the levels of lysine, methionine, isoleucine, phosphatidylcholine, tyrosine, creatine, linoleic acid, glutamine, 3-hydroxybutyrate, valine and citric acid decreased remarkably, while the levels of betaine and cholesterol increased obviously in serum of hyperlipidemia model mice compared to those in the control group. These change trends indicate that hyperlipidemia is closely related to energy metabolism, lipid metabolism and amino acid metabolism.

\section{Metabolites related to energy metabolism}

Creatine is a commonly used as an indicator of renal function, the creatine-phosphocreatine system is crucial for mitochondria transport energy production, and the decrease level of creatine in hyperlipidemia model group can taken as a disruption signal of energy homeostasis [26]. Recently metabolomic studies have reported that the reduced level of serum creatine is related to steatosis and non-alcoholic fatty liver disease [27-29]. Citric acid, as one of the important intermediates in the tricarboxylic acid cycle (TCA cycle), is involved in the physiological oxidation of fats, proteins, and carbohydrates to carbon dioxide and water, a decreased level of citric acid 
Table 2 Data of identified metabolites detected by RRLC-Q-TOF/MS

\begin{tabular}{|c|c|c|c|c|c|c|}
\hline lon mode & Metabolite & Mass & Molecular formula & Related pathway & Changes (M-C) & Changes (S-M) \\
\hline \multirow[t]{9}{*}{ Negative } & Lysine & 146.1876 & $\mathrm{C}_{6} \mathrm{H}_{14} \mathrm{~N}_{2} \mathrm{O}_{2}$ & Amino acid metabolism & $\downarrow$ & $\uparrow$ \\
\hline & Creatine & 113.1179 & $\mathrm{C}_{4} \mathrm{H}_{7} \mathrm{~N}_{3} \mathrm{O}$ & Energy metabolism & $\downarrow$ & $\uparrow$ \\
\hline & Methionine & 149.2113 & $\mathrm{C}_{5} \mathrm{H}_{11} \mathrm{NO}_{2} \mathrm{~S}$ & Amino acid metabolism & $\downarrow$ & $\uparrow$ \\
\hline & Glutamine & 146.1445 & $\mathrm{C}_{5} \mathrm{H}_{10} \mathrm{~N}_{2} \mathrm{O}_{3}$ & Amino acid metabolism & $\downarrow$ & - \\
\hline & Isoleucine & 131.1729 & $\mathrm{C}_{6} \mathrm{H}_{13} \mathrm{NO}_{2}$ & Amino acid metabolism & $\downarrow$ & - \\
\hline & Linoleic acid & 280.4455 & $\mathrm{C}_{18} \mathrm{H}_{32} \mathrm{O}_{2}$ & Fatty acid metabolism & $\downarrow$ & $\uparrow$ \\
\hline & Tyrosine & 181.1885 & $\mathrm{C}_{9} \mathrm{H}_{11} \mathrm{NO}_{3}$ & Amino acid metabolism & $\downarrow$ & $\uparrow$ \\
\hline & Valine & 117.1463 & $\mathrm{C}_{5} \mathrm{H}_{11} \mathrm{NO}_{2}$ & Amino acid metabolism & $\downarrow$ & - \\
\hline & Citric acid & 192.1235 & $\mathrm{C}_{6} \mathrm{H}_{8} \mathrm{O}_{7}$ & TCA cycle & $\downarrow$ & - \\
\hline \multirow[t]{4}{*}{ Positive } & Cholesterol & 386.6535 & $\mathrm{C}_{27} \mathrm{H}_{46} \mathrm{O}$ & Fatty acid metabolism & $\uparrow$ & $\downarrow$ \\
\hline & 3-hydroxybutyrate & 104.1045 & $\mathrm{C}_{4} \mathrm{H}_{8} \mathrm{O}_{3}$ & Lipid metabolism & $\downarrow$ & $\uparrow$ \\
\hline & Betaine & 117.1463 & $\mathrm{C}_{5} \mathrm{H}_{11} \mathrm{NO}_{2}$ & Amino acid metabolism & $\uparrow$ & $\downarrow$ \\
\hline & Phosphatidylcholine & 758.0603 & $\mathrm{C}_{42} \mathrm{H}_{80} \mathrm{NO}_{8} \mathrm{P}$ & Lipid metabolism & $\downarrow$ & $\uparrow$ \\
\hline
\end{tabular}

Note: M-C represented hyperlipidemia model group vs. control group; S-M represented SCL group vs. hyperlipidemia model group. " $\uparrow$ " and " $\downarrow$ " indicated that the compound was up- and down-regulated; "-" indicated that the compound did not significantly change

also indicates a glycolysis inhibition and energy metabolism dysfunction in hyperlipidemia model mice [30]. In this study, the levels of creatine $(P<0.05)$ and citric acid $(P<0.01)$ decreased obviously in the model group compared with that in the control group, while the creatine level in model + SCL group $(P<0.05)$ increased obviously compared with that in the model group. These results suggest that SCL could prevent the renal damage caused by lipid disorders.

\section{Metabolites related to amino acids}

Amino acids, as substrates for protein synthesis, gluconeogenesis and ketogenesis, can also provide energy through TCA cycle [31, 32]. Valine, isoleucine and tyrosine are branched chain amino acids, playing an important role in promoting protein synthesis, glucose metabolism, oxidation and regulating leptin secretion. High levels of them contribute to obesity-related insulin resistance and glucose intolerance [33-35]. Isoleucine and valine are also

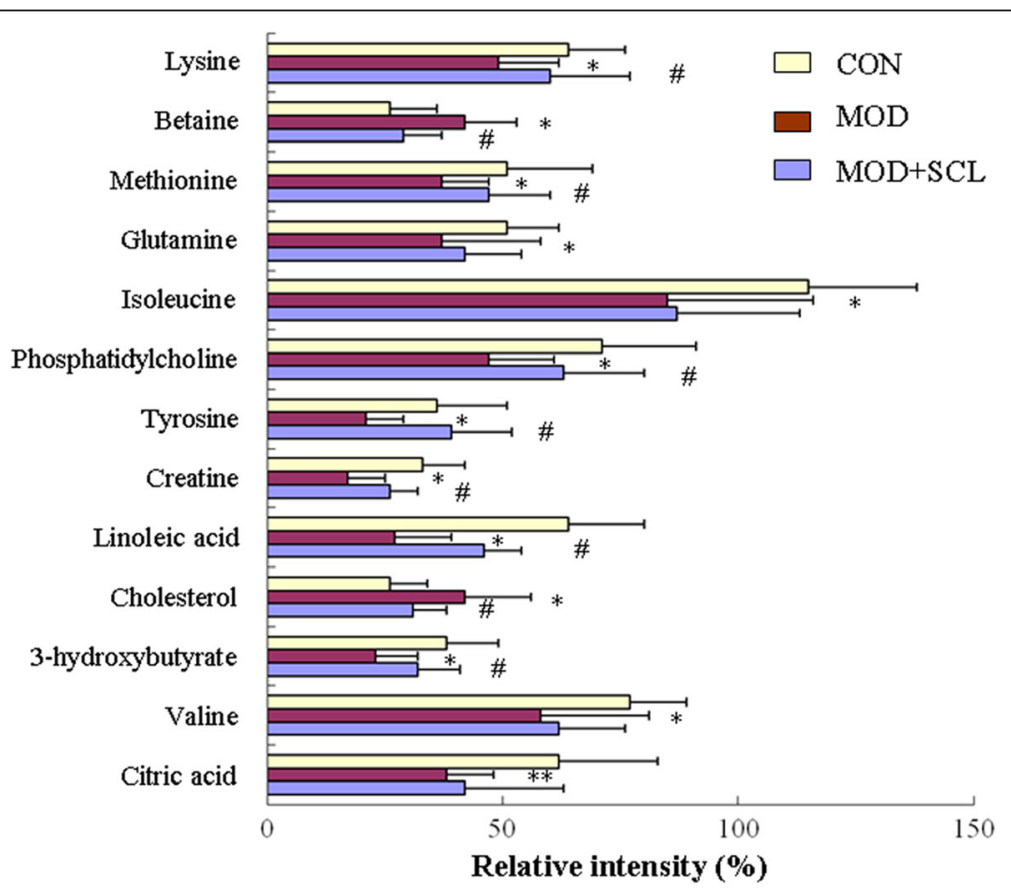

Fig. 6 Comparison of the relative intensity of potential biomarkers in control, model and model + SCL group. Note: Values are expressed as mean \pm standard deviation (SD). *: $P<0.05$ and **: $P<0.01$ compared with the control group; $: P<0.05$ compared with the model group 

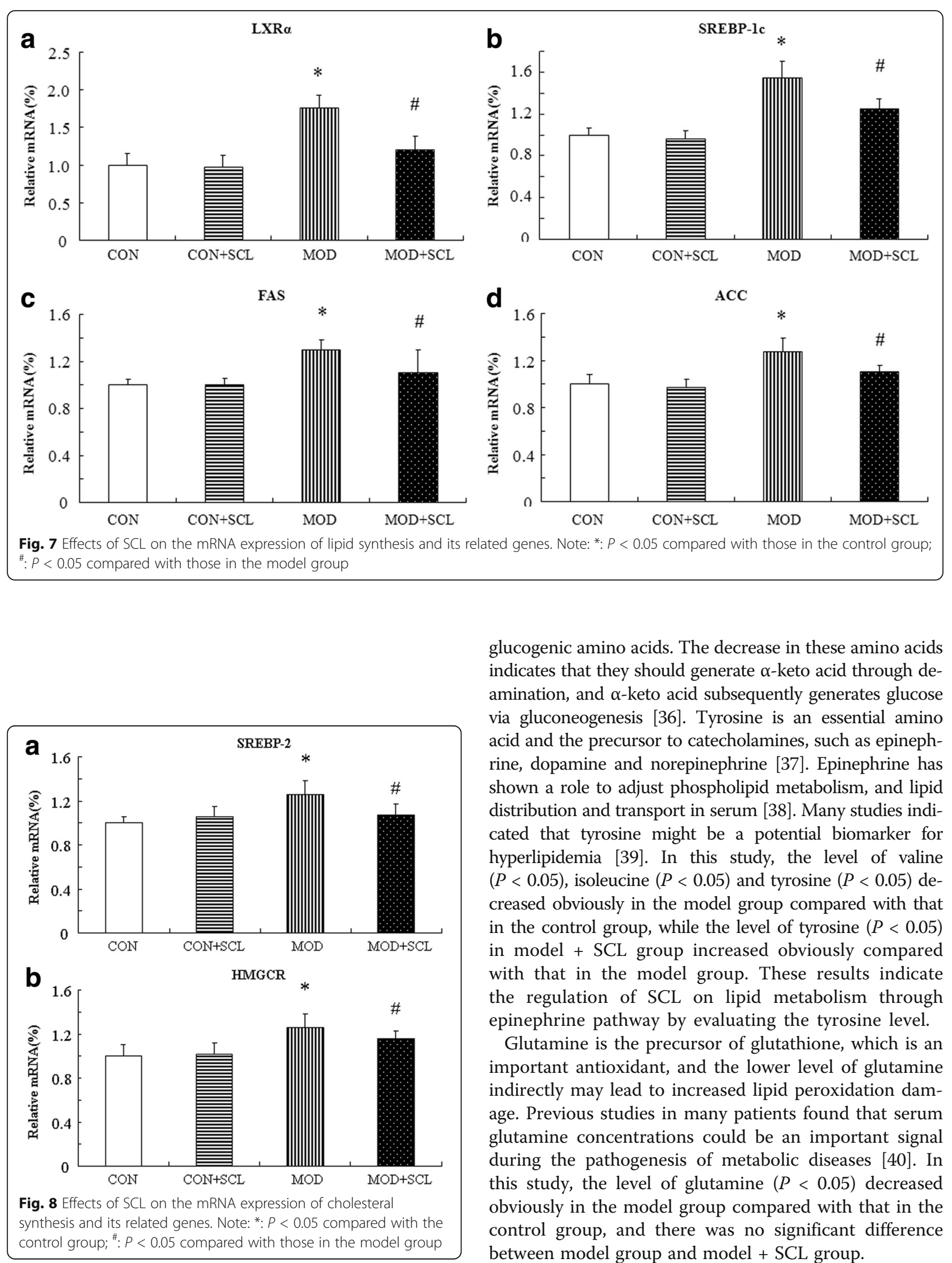

glucogenic amino acids. The decrease in these amino acids indicates that they should generate $\alpha$-keto acid through deamination, and $\alpha$-keto acid subsequently generates glucose via gluconeogenesis [36]. Tyrosine is an essential amino acid and the precursor to catecholamines, such as epinephrine, dopamine and norepinephrine [37]. Epinephrine has shown a role to adjust phospholipid metabolism, and lipid distribution and transport in serum [38]. Many studies indicated that tyrosine might be a potential biomarker for hyperlipidemia [39]. In this study, the level of valine $(P<0.05)$, isoleucine $(P<0.05)$ and tyrosine $(P<0.05)$ decreased obviously in the model group compared with that in the control group, while the level of tyrosine $(P<0.05)$ in model + SCL group increased obviously compared with that in the model group. These results indicate the regulation of SCL on lipid metabolism through epinephrine pathway by evaluating the tyrosine level.

Glutamine is the precursor of glutathione, which is an important antioxidant, and the lower level of glutamine indirectly may lead to increased lipid peroxidation damage. Previous studies in many patients found that serum glutamine concentrations could be an important signal during the pathogenesis of metabolic diseases [40]. In this study, the level of glutamine $(P<0.05)$ decreased obviously in the model group compared with that in the control group, and there was no significant difference between model group and model + SCL group. 
The lysines in albumin- and apoB100- containing particles can generate glycosylation end products or can be further oxidized [41, 42], thus the lower free lysine level in hyperlipidemia group might indicate the occurrence of oxidative stress in the pathogenesis of hyperlipidemia, which might aggravate fatty liver disease and fat accumulation. The level of lysine $(P<0.05)$ decreased obviously in the model group compared with that in the control group, while SCL administration caused the increase of lysines level $(P<0.05)$ compared with the model group in our study. This result may implicate that anti-oxidative activity should be one of the possible properties of the SCL.

Methionine is an intermediate in a transmethylation reaction that uses $\mathrm{S}$-adenosyl methionine as a methyl donor to homocysteine [43]. By acting as a methyl donor during the remethylation of homocysteine, betaine converts homocysteine into methionine and helps maintain the appropriate level of S-adenosyl methionine. Betaine was discovered to be the most important variable in predicting hyperlipidemia, and could be considered an early biomarker of coronary heart disease [44, 45]. Our study showed a lower level of methionine $(P<0.05)$ while higher level betaine $(P<0.05)$ in hyperlipidemia group, and the levels of methionine and betaine returned to normal levels after SCL administration. These results suggest that SCL can regulate the methionine/homocysteine cycle enhancement of hyperlipidemia and reduce the risk of cardiovascular diseases.

\section{Metabolites related to lipid metabolism}

Lipid metabolism disorder is the most obvious manifestation of the development of hyperlipedemia. Phosphatidylcholine, as the most predominant lipid in the HDL fraction [46], can affect the deposition of lipids and cholesterol by removing excessive triglycerides and improving the solubility of cholesterol and lipids in the serum [36]. In this study, phosphatidylcholine level showed an obviously decrease in model group serum compared with that in the control group $(P<0.05)$, and an increase in SCL group compared with that in the model group. These changes were consistent with the results of HDLc level in serum.

Linoleic acid is an essential fatty acid and exclusively reflects the dietary intake [47]. Recent research has reported linoleic plays an important role in reducing the serum TC and LDL-c levels [48]. As a polyunsaturated fatty acid, linoleic acid is a precursor of prostaglandins via the arachidonic acid pathway. Prostaglandins have many beneficial effects against cardiovascular risk, including hyperlipidemia and essential hypertension $[49,50]$. The level of linoleic acid decreased $(P<0.05)$ obviously in the model group compared with that in the control group, while SCL administration caused an increase in linoleic acid level $(P<0.05)$ compared with model group in our study. According to the experimental results of serum TC and LDL-C, this result indicates that SCL can regulate TC and LDL-c disorder through linoleic acid pathway.

Cholesterol is an important biomarker of hyperlipidemia, and its high serum level in hyperlipedemia model group $(P<0.05)$ and its returning to the normal level after SCL administration $(P<0.05)$ in this metabolism study were consistent with those by the serum lipid measurement.

3-hydroxybutyrate is generally considered to be ketone body, produced by aceoacetate and acetyl-CoA. It was previously reported that the decrease in 3-hydroxybutyrate demonstrated that hyperlipidemia could lead to the accumulation of ketone body and the conversion of acetoacetate transfers towards the production of acetone [36]. The level of 3-hydroxybutyrate decreased $(P<0.05)$ obviously in the model group compared with that in the control group, while SCL administration caused an increased 3hydroxybutyrate level $(P<0.05)$ compared with the model group in our study, indicating that SCL can regulate acetylCoA to restore the disorder of hyperlipedemia metabolism.

In summary, SCL treatment partially recovered the metabolism disorders induced by high-lipid diet and exerted a good anti-hyperlipidemia effect. The metabolic pathways included were proposed as follows: TCA cycle, synthesis of ketone body and cholesterol, choline metabolism, and fatty acid metabolism (Fig. 9).

\section{Effects of SCL on the mRNA expression of lipid/cholesterol metabolism-related genes in hyperlipidemic mice}

Liver is an important organ of regulating lipid metabolism balance. The key enzymes of liver fatty acid synthesis, acetyl-CoA carboxylase (ACC) and fatty acid synthase (FAS), are regulated by the nuclear transcription factor SREBP-1c [51]. The related experiments have confirmed that in transgenic mice, ob/ob mice (the insulin resistance and hyperinsulinemia caused by leptin deficiency), mice and rats on diets containing higher cholesterol, other hyperlipidemia animals models, and patients with high blood lipids, the expressions of SREBP-1c and its lipid synthesis-regulated target genes in the livers, including FAS and ACC expression, were increased several times, resulting in a large number of TG deposition [52-56], and the gene expression of SREBP-1c is regulated by the nuclear liver X-activated receptor- $\alpha(\mathrm{LXR} \alpha)$. The activation of LXR can increase the expression of SREBP-1c, FAS and ACC genes, causing an increase in the content ratio of TG [57]. In addition, the expression of LXR $\alpha /$ SREBP-1c is significantly increased in animals and patients with hyperlipidemia, showing a positive correlation [58]. Consistent with these findings, our results indicated that the expressions of LXR $\alpha$, SREBP- 1 and its target genes, and ACC and FAS, were significantly increased in the liver tissues 


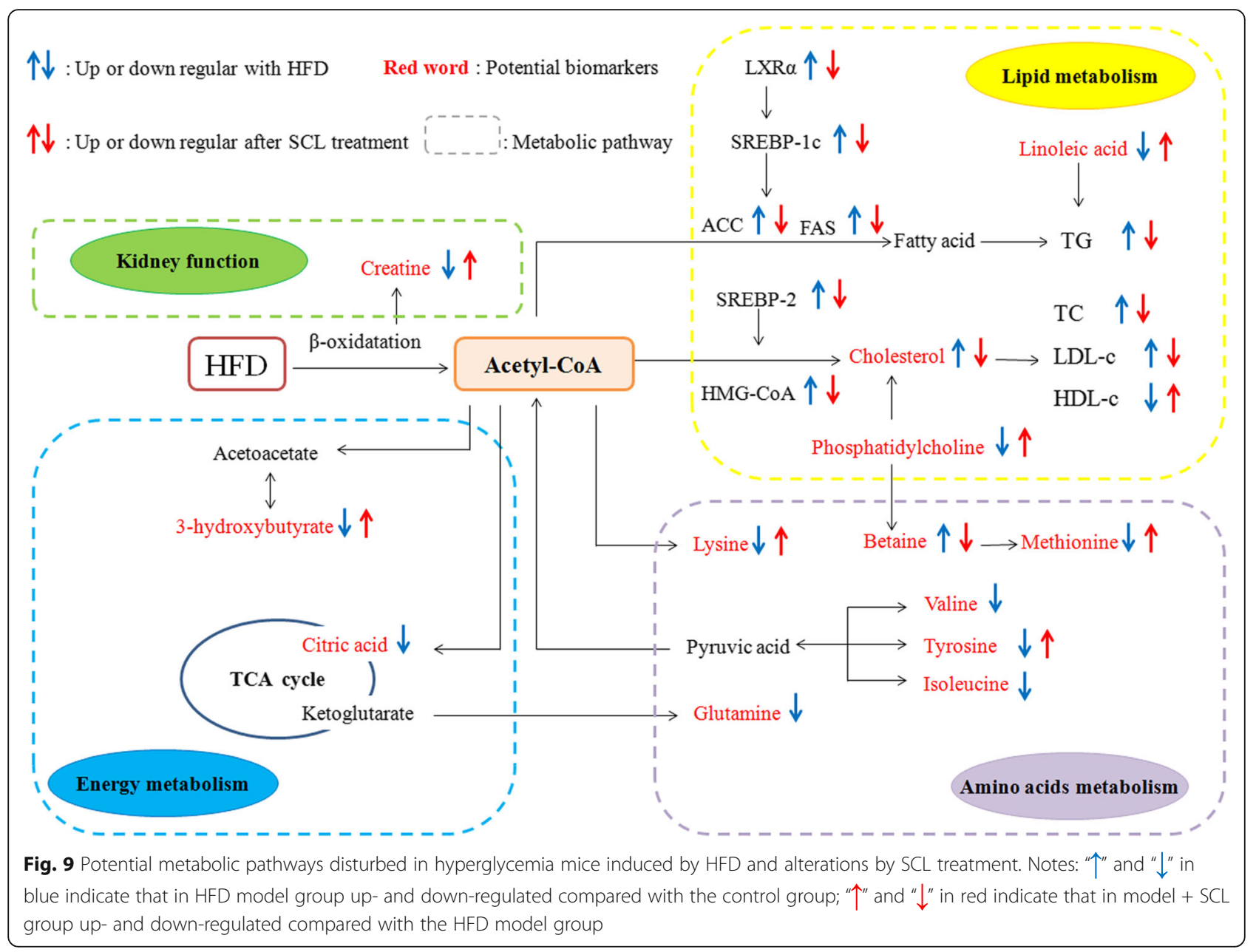

of hyperlipidemia mice on the high-fat diet for 4 weeks, while the administration of SCL could down-regulate the expression of LXR $\alpha / S R E B P-1 c$ signal, and then reduce the expression of FAS and ACC, thereby reducing the production of TG and fatty acid and the lipid accumulation in the liver.

Moreover, we found that the administration of SCL could also significantly decrease the expression of hepatic cholesterol metabolism key regulatory factors SREBP-2 and HMGCR in hyperlipidemia mice. In recent years, besides fatty acids, the abnormality of cholesterol metabolism and its toxicities in hyperlipidemia, especially the important role in the pathogenesis of NASH, have aroused a wide concern of many researchers [59]. Puri, et al. found that the free cholesterol level in the liver of patients with NASH increased significantly [60]. Then Caballero, et al. confirmed that not only free cholesterol but also SREBP-2 levels were also significantly increased in patients with hyperlipidemia [61]. Furthermore, it is well known that the excessive free cholesterol can be oxidized to oxidized cholesterol, and the oxidized cholesterol can up-regulate the synthesis of fatty acids and triglycerides by activating
LXR $\alpha /$ SREBP-1c pathway, further promoting the accumulation of fat [62-64]. In this study, the expression of SREBP-2 and its target genes HMGCR was significantly increased in the liver of mice with hyperlipidemia induced by HFD and the administration of SCL could decrease the expression of key factors of cholesterol synthesis, reduce the cholesterol synthesis and alleviate the toxicity of cholesterol in the mice.

\section{Conclusions}

In the present work, anti-hyperlipidemia effect of Schisandra Chinensis lignans was confirmed by both serum biochemistry and metabolomics analysis. We employed RRLC-Q-TOF-MS-based metabolomics approaches to reveal metabolism regulations of SCL on hyperlipidemia mice induced by HFD feeding. It turned out that the administration of SCL could partially recover the metabolism dysfunction caused by hyperlipidemia via the possible metabolic pathways: TCA cycle, synthesis of ketone body and cholesterol, choline metabolism and fatty acid metabolism. The mechanism may be related to the down-regulation of LXR $\alpha /$ SREBP-1c/FAS/ACC 
and SREBP2/HMGCR signaling pathways, which may provide a theoretical basis for the prevention and treatment of hyperlipidemia.

\section{Abbreviations \\ ACC: acetyl-CoA carboxylase; FAS: fatty acid synthase; HDL-c: high-density lipoprotein cholesterol; HFD: high-fat diet; HMGCR: 3-hydroxy-3-methylglutaryl coenzyme A reductase.; KEGG: Kyoto Encyclopedia of Genes and Genomes; LDL-c: low-density lipoprotein cholesterol; LXRa: liver X receptor a; PCA: principal component analysis; PLS-DA: partial least squares-discriminant analysis; RRLC-Q- TOF-MS: rapid resolution liquid chromatography coupled with quadruple-time- of-flight mass spectrometry; RT-PCR: real-time polymerase chain reaction; SCL: Schisandra Chinensis lignans; SREBPs: sterol regulatory element-binding proteins; TC: total cholesterol; TCA: tricarboxylic acid; TG: triglyceride}

\section{Acknowledgments}

Not applicable.

\section{Funding}

This project was supported by the Natural Science Foundation of Jilin Province (20170307016YY; 20150101230JC; 20150311047YY).

\section{Availability of data and materials}

The datasets analyzed during the current study are available from the corresponding author on reasonable request.

\section{Authors' contributions}

Design of the study: JHS, CMW; conducts of the study: XL, LXC; data collection: HL, CYZ; data analysis: JHS, JGC; data interpretation: JHS, JGC; manuscript writing: JHS, CMW. All authors read and approved the final manuscript.

\section{Ethics approval and consent to participate}

The animal study proposal was approved by the Institutional Animal Care and Use Committee (IACUC) of Beihua University with the permit number: CPBHU IACUC2015-007.

\section{Consent for publication}

Not applicable.

\section{Competing interests}

The authors declare that have no competing interests.

\section{Author details}

'College of Pharmacy, Beihua University, 3999 Binjiang East Road, Jilin 132013, China. ${ }^{2}$ Second Treatment Area of Senile Disease, First Affiliated Hospital of Changchun University of Traditional Chinese Medicine, 1478, Gongnong Road, Changchun 130021, China.

Received: 15 February 2017 Accepted: 4 July 2017

Published online: 01 August 2017

\section{References}

1. O'Keefe JH, Bell DS. Postprandial hyperglycemia/hyperlipidemia (postprandial dysmetabolism) is a cardiovascular risk factor. Am J Cardiol. 2007:100(5):899-904

2. Fazio S, Linton MRF. The role of fibrates in managing hyperlipidemia: mechanisms of action and clinical efficacy. Curr Atheroscler Rep. 2004;6(2):148-57.

3. Farnier M, Davignon J. Current and future treatment of hyperlipidemia: the role of statins. Am J Cardiol. 1998:82(4):3J-10J.

4. Saydah SH, Fradkin J, Cowie CC. Poor control of risk factors for vascular disease among adults with previously diagnosed diabetes. JAMA. 2004; 291(3):335-42

5. Jr IW. Clinical utility of bile acid sequestrants in the treatment of dyslipidemia: a scientific review. South Med J. 2006:99(3):257-73.

6. Asbach P, Paetsch I, Stawowy P, Sander B, Fleck E. Statin-associated focal myositis. Int J Cardiology. 2009;133(1):e33-4

7. Wu J, Song Y, Li H, Chen J. Rhabdomyolysis associated with fibrate therapy: review of 76 published cases and a new case report. Eur J Clin Pharmacol. 2009;65(12):1169-74

8. Chiu PY, Mak DH, Poon MK, Ko KM. In vivo antioxidant action of a lignanenriched extract of Schisandra fruit and an anthraquinone-containing extract of Polygonum root in comparison with schisandrin B and emodin. Planta Med. 2002:68(11):951-6.

9. Panossian A, Wikman G. Pharmacology of Schisandra Chinensis bail.: an overview of Russian research and uses in medicine. J Ethnopharmacol. 2008; 118(2):183-212

10. Xie W, Du L. Diabetes is an inflammatory disease: evidence from traditional Chinese medicines. Diabetes Obes Metab. 2011;13(4):289-301.

11. Sun N, Pan SY, Zhang Y, Wang XY, Zhu PL, Chu ZS, Yu ZL, Zhou SF, Ko KM. Dietary pulp from Fructus Schisandra Chinensis supplementation reduces serum/hepatic lipid and hepatic glucose levels in mice fed a normal or high cholesterol/bile salt diet. Lipids Health Dis. 2014;13(1):46.

12. Wat E, Ng CF, Wong EC, Koon CM, Lau CP, Cheung DW, Fung KP, Lau CB, Leung PC. The hepatoprotective effect of the combination use of Fructus Schisandrae with statin-a preclinical evaluation. J Ethnopharmacol. 2015;178:104-14.

13. Chu ZS, Yu ZL, Pan SY, Jia ZH, Wang XY, Zhang Y, Zhu PL, Wang XJ, Ko KM. A comparative study between Wuweizi seed and its post-ethanol extraction residue in normal and hypercholesterolemic mice. Lipids Health Dis. 2015; 14(1):1-12.

14. Ellis DI, Dunn WB, Griffin JL, Allwood JW, Goodacre R. Metabolic fingerprinting as a diagnostic tool. Pharmacogenomics. 2007;8(9):1243-66.

15. Legg K. Metabolomics: gaining insight into pain. Nat Rev Drug Discov. 2012; 11(3):188-9.

16. Nicholson JK. Metabonomics in pharmaceutical R\&D. FEBS J. 2007;274(5): $1140-51$.

17. Zhang Q, Wang GJ. A JY, ma B, Dua Y, Zhu L, Wu D. Metabonomic profiling of diet-induced hyperlipidaemia in a rat model. Biomarkers. 2009;15(3):205-16.

18. Martin JC, Canlet C, Delplanque B, Agnani G, Lairon D, Gottardi G, Bencharif $K$, Gripois D, Thaminy A, Paris A. 1H NMR metabonomics can differentiate the early atherogenic effect of dairy products in hyperlipidemic hamsters. Atherosclerosis. 2009:206(1):127-33.

19. Zha WB. A JY, Wang GJ, Yan B, Gu S, Zhu X, Hao H, Huang Q, sun J, Zhang $Y$, Cao B, Ren $\mathrm{H}$. Metabonomic characterization of early atherosclerosis in hamsters with induced cholesterol. Biomarkers. 2009;14(6):372-80.

20. Gu Y, Zhang Y, Shi X, Li X, Hong J, Chen J, Gu W, Lu X, Xu G, Ning G. Effect of traditional Chinese medicine berberine on type 2 diabetes based on comprehensive metabonomics. Talanta. 2010;81(3):766-72.

21. Liu F, Gan PP, Wu H, Woo WS, Ong ES, Li SF. A combination of metabolomics and metallomics studies of urine and serum from hypercholesterolaemic rats after berberine injection. Anal Bioanal Chem. 2012;403(3):847-56.

22. http://www.hmdb.ca/. Accessed 15 May 2016.

23. http://www.lipidmaps.org/. Accessed 15 May 2016.

24. http://www.genome.jp/kegg/. Accessed 20 May 2016.

25. Munshi RP, Joshi SG, Rane BN. Development of an experimental diet model in rats to study hyperlipidemia and insulin resistance, markers for coronary heart disease. Indian J Pharmacol. 2014;46(3):270-6.

26. Sun YJ, Wang HP, Liang YJ, Yang L, Li W, Wu YJ. An NMR-based metabonomic investigation of the subacute effects of melamine in rats. J Proteome Res. 2012;11(4):2544-50.

27. Kalhan SC, Guo L, Edmison J, Dasarathy S, McCullough AJ, Hanson RW, Millburn M. Plasma metabolomic profile in nonalcoholic fatty liver disease. Metabolism. 2011:60(3):404-13

28. Mallin K, McCann K, D'Aloisio A, Freels S, Piorkowski J, Dimos J, Persky V. Cohort mortality study of capacitor manufacturing workers, 1944-2000. J Occup Environ Med. 2004;46(6):565-76.

29. Barr J. Liquid chromatography-mass spectrometry-based parallel metabolic profiling of human and mouse model serum reveals putative biomarkers associated with the progression of nonalcoholic fatty liver disease. Behav Ecol. 2010;9(9):4501-12.

30. Jiang CY, Yang KM, Yang L, Miao ZX, Wang YH, Zhu HB. A (1)H NMR-based Metabonomic investigation of time-related metabolic trajectories of the plasma, urine and liver extracts of Hyperlipidemic hamsters. PLoS One. 2012; 8(6):e66786.

31. Lopansri BK, Anstey NM, Stoddard GJ, Mwaikambo ED, Boutlis CS, Tjitra E, Maniboey H. Hobbs MR, Levesque MC, Weinberg JB, Granger DL. Elevated plasma phenylalanine in severe malaria and implications for pathophysiology of neurological complications. Infect Immun. 2006:74(6):3355-9.

32. Miao H, Chen $H$, Zhang X, Yin L, Chen DQ, Cheng XL, Bai X, Wei F. Urinary metabolomics on the biochemical profiles in diet-induced hyperlipidemia rat using Ultraperformance liquid chromatography coupled with Quadrupole time-of-flight SYNAPT high-definition mass spectrometry. J Anal Methods Chem. 2014;2014(11):184162. 
33. Holecek M. The BCAA-BCKA cycle: its relation to alanine and glutamine synthesis and protein balance. Nutrition. 2001;17(1):70.

34. Doi M, Yamaoka I, Nakayama M, Sugahara K, Yoshizawa F. Hypoglycemic effect of isoleucine involves increased muscle glucose uptake and whole body glucose oxidation and decreased hepatic gluconeogenesis. Am J Physiol Endocrinol Metab. 2007:292(6):E1683-93.

35. Lynch CJ, Gern B, Lloyd C, Hutson SM, Eicher R, Vary TC. Leucine in food mediates some of the postprandial rise in plasma leptin concentrations. Am J Physiol Endocrinol Metab. 2006;291(3):E621-30.

36. Wang M, Wang F, Wang YN, Ma X, Zhao M, Zhao C. Metabonomics study of the therapeutic mechanism of Gynostemma pentaphyllum and atorvastatin for hyperlipidemia in rats. PLoS One. 2013;8(11):e78731

37. Udenfriend S, Wyngaarden JB. Precursors of adrenal epinephrine and norepinephrine in vivo. Biochim Biophys Acta. 1956;20(1):48-52.

38. Dury A. Effects of epinephrine on lipid partition and metabolism in the rabbit. Circ Res. 1957;5(1):47-53.

39. Zhang Q, Wang GJ. A JY, Wu D, Zhu LL, ma B, du Y. Application of GC/MSbased metabonomic profiling in studying the lipid-regulating effects of Ginkgo biloba extract on diet-induced hyperlipidemia in rats. Acta Pharmacol Sin. 2009;30(12):1674-87.

40. Melis GC, Ter WN, Boelens PG, van Leeuwen PA. Glutamine: recent developments in research on the clinical significance of glutamine. Curr Opin Clin Nutr Metab Care. 2004;7(1):59-70.

41. Ahmed N, Thornalley PJ. Chromatographic assay of glycation adducts in human serum albumin glycated in vitro by derivatization with 6aminoquinolyl-N-hydroxysuccinimidyl-carbamate and intrinsic fluorescence. Biochem J. 2002;364(Pt 1):15-24.

42. Oörni K, Pentikäinen MO, Annila A, Kovanen PT. Oxidation of low density lipoprotein particles decreases their ability to bind to human aortic proteoglycans. Dependence on oxidative modification of the lysine residues. J Biol Chem. 1997;272(34):21303-11.

43. Toborek M, Kopieczna-Grzebieniak E, Drózdz M, Wieczorek M. Increased lipid peroxidation as a mechanism of methionine-induced atherosclerosis in rabbits. Atherosclerosis. 1995;115(2):217-24.

44. Bertram HC, Larsen LB, Chen X, Jeppesen PB. Impact of high-fat and highcarbohydrate diets on liver metabolism studied in a rat model with a systems biology approach. J Agric Food Chem. 2012;60(2):676-84.

45. Lentz SR. Mechanisms of homocysteine-induced atherothrombosis. J Thromb Haemost. 2005;3(8):1646-54.

46. Duarte IF, Goodfellow BJ, Barros A, Jones JG, Barosa C, Diogo L, Garcia P, Gil AM. Metabolic characterisation of plasma in juveniles with glycogen storage disease type 1a (GSD1a) by high-resolution 1H NMR spectroscopy. NMR Biomed. 2007;20(4):401-12.

47. Yamamoto N, Saitoh M, Moriuchi A, Nomura M, Okuyama H. Effect of dietary alpha-linolenate/linoleate balance on brain lipid compositions and learning ability of rats. J Lipid Res. 1987;28(2):144-51.

48. Wijendran V, Hayes KC. Dietary n-6 and n-3 fatty acid balance and cardiovascular health. Annu Rev Nutr. 2004;24(24):597-615.

49. Russo GL. Dietary n-6 and n-3 polyunsaturated fatty acids: from biochemistry to clinical implications in cardiovascular prevention. Biochem Pharmacol. 2009;77(6):937-46.

50. Das UN. Essential fatty acids: biochemistry, physiology and pathology. Biotechnol J. 2006;1(4):420-39.

51. Daemen $\mathrm{S}$, Kutmon M, Evelo CT. A pathway approach to investigate the function and regulation of SREBPs. Genes Nutr. 2013;8(3):289-300.

52. Horton JD, Goldstein JL, Brown MS. SREBPs: activators of the complete program of cholesterol and fatty acid synthesis in the liver. J Clin Invest. 2002;109(9):1125-31.

53. Foufelle F, Ferré P. New perspectives in the regulation of hepatic glycolytic and lipogenic genes by insulin and glucose: a role for the transcription factor sterol regulatory element binding protein-1c. Biochem J. 2002;366(Pt 2):377-91.

54. Horton JD, Shah NA, Warrington JA, Anderson NN, Park SW, Brown MS, Goldstein JL. Combined analysis of oligonucleotide microarray data from transgenic and knockout mice identifies direct SREBP target genes. Proc Natl Acad Sci U S A. 2003;100(21):12027-32.

55. Morgan K, Uyuni A, Nandgiri G, Mao L, Castaneda L, Kathirvel E, French SW, Morgan TR. Altered expression of transcription factors and genes regulating lipogenesis in liver and adipose tissue of mice with high fat diet-induced obesity and nonalcoholic fatty liver disease. Eur J Gastroenterol Hepatol. 2008;20(9):843-54.

56. Min HK, Kapoor A, Fuchs M, Mirshahi F, Zhou H, Maher J, Kellum J, Warnick $\mathrm{R}$, Contos MJ, Sanyal AJ. Increased hepatic synthesis and dysregulation of cholesterol metabolism is associated with the severity of nonalcoholic fatty liver disease. Cell Metab. 2012;15(5):665-74.

57. Repa JJ, Liang G, Ou J, Bashmakov Y, Lobaccaro JM, Shimomura I, Shan B, Brown MS, Goldstein JL, Mangelsdorf DJ. Regulation of mouse sterol regulatory element-binding protein-1c gene (SREBP-1c) by oxysterol receptors. LXRalpha and LXRbeta Genes Dev. 2000;14(22):2819-30.

58. Lima-Cabello E, García-Mediavilla MV, Miquilena-Colina ME, Vargas-Castrillón J, Lozano-Rodríguez T, Fernández-Bermejo M, Olcoz JL, González-Gallego J, García-Monzón C, Sánchez-Campos S. Enhanced expression of pro-inflammatory mediators and liver $\mathrm{X}$-receptor-regulated lipogenic genes in non-alcoholic fatty liver disease and hepatitis C. Clin Sci (Lond). 2011;120(6):239-50.

59. Tilg $\mathrm{H}$, Moschen AR. Evolution of inflammation in nonalcoholic fatty liver disease: the multiple parallel hits hypothesis. Hepatology. 2010;52(5):1836-46.

60. Puri P, Baillie RA, Wiest MM, Mirshahi F, Choudhury J, Cheung O, Sargeant C, Contos MJ, Sanyal AJ. A lipidomic analysis of nonalcoholic fatty liver disease. Hepatology. 2007;46(4):1081-90.

61. Caballero F, Fernández A, De Lacy AM, Fernández-Checa JC, Caballería J, García-Ruiz C. Enhanced free cholesterol, SREBP-2 and StAR expression in human NASH. J Hepatol. 2009;50(4):789-96.

62. Rooyen DMV, Farrell GC. SREBP-2: a link between insulin resistance, hepatic cholesterol, and inflammation in NASH. J Gastroenterol Hepatol. 2011;26(5): 789-92.

63. Ahmed $\mathrm{MH}$, Byrne CD. Modulation of sterol regulatory element binding proteins (SREBPS) as potential treatments for non-alcoholic fatty liver disease (NAFLD). Drug Discov Today. 2007;12(17):740-7.

64. Musso G, Gambino R, Cassader M. Cholesterol metabolism and the pathogenesis of non-alcoholic steatohepatitis. Prog Lipid Res. 2013;52(1):175-91.

\section{Submit your next manuscript to BioMed Central and we will help you at every step:}

- We accept pre-submission inquiries

- Our selector tool helps you to find the most relevant journal

- We provide round the clock customer support

- Convenient online submission

- Thorough peer review

- Inclusion in PubMed and all major indexing services

- Maximum visibility for your research

Submit your manuscript at www.biomedcentral.com/submit
Biomed Central 